\title{
Molecular Epidemiology and Risk Factors of
}

\section{Blastocystis sp. Infections Among General Populations in Yunnan Province, Southwestern China}

This article was published in the following Dove Press journal:

Risk Management and Healthcare Policy

Yao Deng, ${ }^{1} *$ Shunxian Zhang, ${ }^{2, *}$ Chaoqun Ning, ${ }^{2}$ Yongkang Zhou, ${ }^{3}$ Xuejiao Teng, ${ }^{2}$ Xiuping $\mathrm{Wu},{ }^{2}$ Yanhong $\mathrm{Chu}^{2}{ }^{2}$ Yingfang $\mathrm{Yu},{ }^{2}$ Jiaxu Chen, ${ }^{2}$ Liguang Tian, ${ }^{2}$ Wei Wang (D)

'Key Laboratory of National Health Commission on Parasitic Disease Control and Prevention, Jiangsu Provincial Key Laboratory on Parasite and Vector Control Technology, jiangsu Institute of Parasitic Diseases, Wuxi 214064, Jiangsu Province, People's Republic of China; ${ }^{2}$ National Institute of Parasitic Diseases, Chinese Center for Disease Control and Prevention, Key Laboratory of National Health Commission on Parasites and Vector Biology, WHO Collaborating Center for Tropical

Diseases, Chinese Center for Tropical Diseases Research, Shanghai 200025, People's Republic of China; ${ }^{3}$ The First Clinical Medical College of Lanzhou University, Lanzhou 730000, Gansu

Province, People's Republic of China

*These authors contributed equally to this work

Correspondence: Liguang Tian National Institute of Parasitic Diseases, Chinese Center for Disease Control and Prevention, Key Laboratory of National Health Commission on Parasites and Vector Biology, WHO Collaborating Center for Tropical Diseases, Chinese Center for Tropical Diseases Research, Shanghai City 200025, People's Republic of China

Email jztlg@I26.com

Wei Wang

Key Laboratory of National Health Commission on Parasitic Disease Control and Prevention, Jiangsu Provincial Key Laboratory on Parasite and Vector

Control Technology, Jiangsu Institute of Parasitic Diseases, Wuxi City, Jiangsu

Province 214064, People's Republic of China

Email wangwei@jipd.com
Background: Blastocystis is a common enteric parasite of controversial pathogenic roles in human diseases. Although the prevalence of Blastocystis infections has been investigated in a diverse range of populations, there is little knowledge on the molecular epidemiology and risk factors of Blastocystis infections among general populations in southeastern China.

Materials and Methods: A total of 507 individuals were randomly selected in Yunnan province, China from July 2016 to March 2017. Stool specimens were sampled for detection of Blastocystis sp. using PCR assay, and the risk factors of Blastocystis infections were identified. Blastocystis isolates were subtyped, and the associations of Blastocystis infections and subtypes with clinical manifestations were examined.

Results: The overall detection rate of Blastocystis sp. was $9.47 \%$ (95\% CI: $7.13-12.44 \%)$. Toilet type $(O R=3.248,95 \%$ CI: $1.245-8.473)$, anemia $(O R=2.601,95 \% C I: 1.245-8.473)$ and type of daily drinking water $(O R=3.11,95 \% C I: 1.557-6.213)$ were identified as risk factors of Blastocystis infections; however, Blastocystis infections showed no associations with clinical symptoms. Four subtypes (ST1 to ST4) were characterized in Blastocystis isolates, in which ST3 was predominant $(4.73 \%, 95 \%$ CI: 3.2-6.94\%), followed by ST1 (3.16\%, 95\% CI: $1.95-5.07 \%)$, ST4 (1.38\%, 95\% CI: 0.07-2.82\%) and ST2 (0.2\%, 95\% CI: $0-1.11 \%)$. In addition, ST1 subtype infection was found to correlate with anemia $(O R=4.66$, 95\% CI: 1.631-14.314).

Conclusions: There is a high prevalence of Blastocystis infections among general populations in Yunnan province, southwestern China, and toilet type, anemia and type of daily drinking water are risk factors of Blastocystis infections. ST3 is the dominant subtype of Blastocystis sp. characterized, and ST1 correlates with anemia. Improving hygiene conditions, developing healthy lifestyles and intensifying health education programs are strongly recommended to reduce the prevalence and transmission potential of Blastocystis infections. Keywords: Blastocystis sp., molecular epidemiology, risk factor, subtype, clinical manifestation, southwestern China

\section{Introduction}

The single-celled protozoan Blastocystis, which was firstly characterized in 1912, is one of the most common enteric parasites that inhabits the gastrointestinal tract of humans and many animals with global distribution. ${ }^{2}$ The prevalence of human Blastocystis sp. infections varies greatly in countries, ranging from $1.26 \%$ to $70 \% .^{3}$ More importantly, the prevalence of human Blastocystis sp. infections appears a tendency towards a rise over years across the world. ${ }^{4}$ 
Epidemiological studies have shown that Blastocystis sp. infections predominantly occur in immunocompromised individuals and those with close contacts with animals. ${ }^{5}$ Human infections may manifest diverse clinical syndromes, and severe infections may present abdominal pain, diarrhea, weakness and fever. ${ }^{6}$ Although the pathogenic role of Blastocystis sp. remains controversial, ${ }^{5}$ this intestinal pathogen is linked to gastrointestinal disorders, ${ }^{7-10}$ urticaria $^{11-14}$ and Steven Johnson's syndrome. ${ }^{15}$ In addition, Blastocystis sp. infection may cause a growth stunting and a reduction in cognitive and learning abilities and quality of life in children. ${ }^{16,17}$ There is increasing evidence proving that Blastocystis sp. infection poses a great threat to human health, ${ }^{18}$ and some Blastocystis subtypes show pathogenic potential. ${ }^{19}$ In animal models experimentally infected with Blastocystis sp., the Blastocystis subtype 1 (ST1) was found to be associated with elevated pathogenicity. $^{20}$ In Egyptian urticarial patients, the Blastocystis subtype 3 (ST3) was reported to be linked to chronic idiopathic urticaria. ${ }^{12}$ Infection with different Blastocystis subtypes may present diverse clinical manifestations; however, the underlying mechanisms remain to be investigated.

In China, Blastocystis sp. human infections have been detected in more than 12 provinces, and the overall prevalence was $3.37 \%$ (range, $0.8 \%$ to $100 \%$ ), ${ }^{21}$ and multiple risk factors have been identified for Blastocystis sp. human infections, including poor hygiene conditions, not washing hands after using toilets, hepatitis B virus infection, keep pets at home, drinking non-tap water. ${ }^{22-25}$ Although a high prevalence of Blastocystis sp. human infections has been reported in rural areas of China, ${ }^{26-28}$ there is little knowledge on the molecular epidemiology and subtypes of Blastocystis sp. in many parts of China, notably in impoverished and underprivileged communities from rural and remote areas, which are of the great need for public health interventions. This cross-sectional study was therefore designed to investigate the molecular epidemiology and risk factors for Blastocystis sp. infections among general populations living in remote, impoverished, and rural communities of Yunnan province, southwestern China.

\section{Materials and Methods}

\section{Ethics Statement}

This study was approved by the Ethical Review Committee of National Institute of Parasitic Diseases, Chinese Center for Disease Control and Prevention. All experimental procedures were performed in accordance with the Declaration of Helsinki, and written informed consent was obtained from all participants following a detailed description of the purpose, potential risks and benefits of the study. Participation was voluntary and individuals were free to withdraw from the study at any time without further obligations.

\section{Study Subjects}

A cross-sectional study was performed during the period between July 1, 2016 and March 31, 2017. Participants were randomly selected from Beihai and Qushi towns in suburban areas of Tengchong city $\left(24^{\circ} 38^{\prime} \mathrm{N}, 98^{\circ} 05^{\prime} \mathrm{E}\right)$, Yunnan province, southwestern China. According to the local government statistics, there were 659,900 residents living in the city, which had a gross domestic product (GDP) of 2.05 billion dollars in 2014, and local residents primarily depend on farming and livestock breeding. As a tropical monsoon climate area, Tengchong city has a mean annual rainfall of $1,135 \mathrm{~mm}$, mean annual temperature of $14.9^{\circ} \mathrm{C}$, and mean elevation of $1,596 \mathrm{~m}$ above sea level. Both towns are agricultural areas, and more than $60 \%$ of local residents live in rural areas. Participants with inadequate fecal samples, unqualified questionnaires, or refusal to participate were excluded from the study.

\section{Questionnaire Survey}

A structured questionnaire was employed to capture the demographic (gender, age, height, body weight, ethnicity, residence, marital status, family size, number of children, occupation and education level) and clinical characteristics (blood pressure, heart rate, abdominal pain, abdominal distension, loss of appetite, itchy skin, perianal pruritus and constipation). In addition, the lifestyle and diet habitats were investigated using the questionnaire survey. All surveys were performed by well-trained doctors or nurses.

\section{Identification of Blastocystis sp. Infections}

Fecal samples (amount $>3 \mathrm{~g}$ or $3 \mathrm{~mL}$ ) were collected from each participant under aseptic conditions, transferred to the laboratory of the Tengchong Center for Disease Control and Prevention within 12 hours, and frozen at $-70^{\circ} \mathrm{C}$. Each frozen stool specimen was delivered to the laboratory of the National Institute of Parasitic Diseases, Chinese Center for Disease Control and Prevention (Shanghai, China), and stored at $-70^{\circ} \mathrm{C}$ for the subsequent experiments.

Blastocystis sp. genomic DNA was extracted from each stool specimen using the QIAamp DNA Stool Mini Kit 
(Qiagen; Hilden, Germany) according to the manufacturer's protocol. Blastocystis sp. was detected using a polymerase chain reaction (PCR) assay with the primers targeting the $18 \mathrm{~S}$ small-subunit ribosomal RNA (SSU $r R N A$ ) coding region gene. ${ }^{29}$ PCR assay was performed in a $25 \mu \mathrm{L}$ of the reaction system containing $12.5 \mu \mathrm{L}$ of 2 $\times$ TaKaRa Taq ${ }^{\text {TM }}$ DNA mixture (TaKaRa Bio Inc, Shiga, Japan), $2 \mu \mathrm{L}$ of DNA template, $1 \mu \mathrm{L}$ of each primer set (forward: 5'-GGAGGTAGTGACAATAAATC-3', reverse: 5'-ACTAGGAATTCCTCGTTCATG-3', each at $10 \mu \mathrm{M}$ ), and $8.5 \mu \mathrm{L}$ of $\mathrm{ddH}_{2} \mathrm{O}$ under the following conditions: at $94^{\circ} \mathrm{C}$ for $5 \mathrm{~min}$; followed by 40 cycles of at $94^{\circ} \mathrm{C}$ for $30 \mathrm{~s}$, at $58^{\circ} \mathrm{C}$ for $1 \mathrm{~min}$, and at $72^{\circ} \mathrm{C}$ for $1 \mathrm{~min}$; and finally at $72^{\circ}$ $\mathrm{C}$ for $10 \mathrm{~min}$. PCR products were checked by electrophoresis on $1 \%$ agarose gels at $120 \mathrm{~V}$ for $40 \mathrm{~min}$ and visualized under UV light following ethidium bromide staining, and the observed size of the PCR amplification product was $1100 \mathrm{bp}$.

\section{Characterization of Blastocystis Subtypes}

The PCR amplification products of suspected positive cases were purified and sequenced on both strands using the dideoxy-terminal method in Sangon Biotech Company (Shanghai, China). ${ }^{30}$ Sequences were edited in the software MEGA version 6.0 (https://www.megasoftware.net/) and aligned with the reference sequences of each Blastocystis sp. subtype retrieved from the GenBank database using BLAST queries, including ST1 (GenBank accession number: U51151), ST2 (GenBank accession number: AB070997 and AB070987), ST3 (GenBank accession number: AB070988 and AB070986), ST4 (GenBank accession number: AY244621 and U51152), ST5 (GenBank accession number: AB070999 and AB107966), ST6 (GenBank accession number: AB070990 and AB070994), ST7 (GenBank accession number: AF408427 and AB070991), ST8 (GenBank accession number: AY266472) and ST9 (GenBank accession number: AY266470).

\section{Statistical Analysis}

All data were processed using the statistical software SPSS version 25.0 (SPSS, Inc.; Chicago, IL, USA). All measurement data were described as the median and interquartile range (IQR), and comparisons of the measurement data between groups were done using Student $t$-test, Wilcoxon rank sum test or Kruskal-Wallis $H$-test. The risk factors of Blastocystis sp. infections were identified using univariate analysis with Fisher exact test and chi-square test, and factors with a $P$ value of $<0.20$ in the univariate analysis were included in the multivariate logistic regression analysis. The associations of Blastocystis sp. infections and subtypes with clinical manifestations were examined using chi-square test or Fisher exact test, and odds ratio $(O R)$ and $95 \%$ confidence intervals $(95 \% C I \mathrm{~s})$ were calculated to measure the strength of the association. A $P$ value of $<0.05$ was considered statistically significant.

\section{Results}

\section{Subject Characteristics}

A total of 507 individuals participated in this study. The subjects included 260 men and 247 women, and had a median age of 49 years ( $95 \%$ CI: $48-51$ years), a mean weight of $57.75 \mathrm{~kg}(95 \%$ CI: $56.77-58.72 \mathrm{~kg})$, a mean height of $160.28 \mathrm{~cm}(95 \%$ CI: $158.88-161.69 \mathrm{~cm})$, a median family size of 4 (95\% CI: 4-5), and a median child number of 1 (95\% CI: 1-2). Among all participants, $94.87 \%$ had a Han ethnicity, $77.71 \%$ lived in rural areas, $65.48 \%$ had an education level of primary school, $63.12 \%$ were farmers and $81.46 \%$ were married. The five most common clinical manifestations included loss of appetite (17.95\%), abdominal pain (17.95\%), abdominal distention (12.43\%), anemia $(12.23 \%)$ and itchy skin (12.23\%) (Table 1).

\section{Prevalence of Blastocystis sp. Infections}

The overall detection rate of Blastocystis sp. was 9.47\% (95\% CI: 7.13-12.44\%) among the participants. There were no significant differences between individuals with and without Blastocystis sp. infections in terms of the median age (Blastocystis-positive individuals: 52 years, 95\% CI: 51-55 years; Blastocystis-negative individuals: 51 years, 95\% $C I$ : $45-61$ years; $Z=-0.065, P=0.948$ ), median height (Blastocystis-positive individuals: $163 \mathrm{~cm}$, 95\% CI: 163-165 cm; Blastocystis-negative individuals: $167.5 \mathrm{~cm}, 95 \%$ CI: $160-168 \mathrm{~cm} ; Z=-1.168, P=0.244$ ) or mean proportion of eosinophilia granulocytes in the peripheral blood (Blastocystis-positive individuals: 2\%, 95\% CI: $1.8-2.3 \%$; Blastocystis-negative individuals: $1.85 \%$, 95\% CI: $1.4-2.6 \% ; Z=-0.212, P=0.832$ ). However, a higher median weight was measured in individuals with Blastocystis infections (60 kg, 95\% CI: 60-62) than in those without Blastocystis infections $(55 \mathrm{~kg}, 95 \% \mathrm{CI}$ : $55-61 \mathrm{~kg})(Z=-2.431, P=0.013)$.

\section{Risk Factors of Blastocystis sp. Infections}

Univariate analysis showed that the prevalence of Blastocystis sp. infections was not associated with age, 
Table I Univariate Analysis of Factors Affecting Blastocystis sp. Infections

\begin{tabular}{|c|c|c|c|c|c|c|c|}
\hline \multirow{2}{*}{\multicolumn{2}{|c|}{ Variable }} & \multicolumn{2}{|c|}{$\begin{array}{l}\text { Blastocysts sp. } \\
\text { Infections (n, \%) }\end{array}$} & \multicolumn{4}{|c|}{ Univariate Analysis } \\
\hline & & \multirow{2}{*}{$\begin{array}{l}\text { Positive } \\
(n=48)\end{array}$} & \multirow{2}{*}{$\begin{array}{l}\text { Negative } \\
(n=459)\end{array}$} & \multirow{2}{*}{$\frac{\chi^{2}}{0.012}$} & \multirow{2}{*}{$\begin{array}{l}P \\
0.914\end{array}$} & \multirow{2}{*}{$\begin{array}{l}\text { OR } \\
0.964\end{array}$} & \multirow{2}{*}{$\begin{array}{l}95 \% \mathrm{Cl} \text { for } \\
\text { OR } \\
0.493,1.833\end{array}$} \\
\hline Age (years) & $\begin{array}{l}<40(n=134) \\
40 \text { or greater }(n=373)\end{array}$ & & & & & & \\
\hline Gender & $\begin{array}{l}\text { Male }(n=260) \\
\text { Female }(n=247)\end{array}$ & $\begin{array}{l}22(8.5) \\
26(10.5)\end{array}$ & $\begin{array}{l}238(91.5) \\
221(89.5)\end{array}$ & 0.63 & 0.427 & 1.273 & $0.70 \mathrm{I}, 2.3 \mathrm{II}$ \\
\hline Ethnicity & $\begin{array}{l}\text { Minority ethnicity }(n=26) \\
\text { Han ethnicity }(n=48 I)\end{array}$ & $\begin{array}{l}3(11.5) \\
45(9.4)\end{array}$ & $\begin{array}{l}23(88.5) \\
436(90.6)\end{array}$ & $-*$ & 0.724 & 0.791 & $0.229,2.739$ \\
\hline Residence & $\begin{array}{l}\text { Urban area }(n=113) \\
\text { Rural area }(n=394)\end{array}$ & $\begin{array}{l}9(8.0) \\
39(9.9)\end{array}$ & $\begin{array}{l}104(92.0) \\
355(90.1)\end{array}$ & 0.383 & 0.536 & 1.269 & $0.595,2.706$ \\
\hline Education level & $\begin{array}{l}\text { Primary school }(n=332) \\
\text { Junior school }(n=111) \\
\text { High school }(n=43) \\
\text { University or College }(n=21)\end{array}$ & $\begin{array}{l}33(9.9) \\
11(9.9) \\
2(4.7) \\
2(9.5)\end{array}$ & $\begin{array}{l}299(90.1) \\
100(90.1) \\
41(95.3) \\
19(90.5)\end{array}$ & 1.518 & 0.678 & -* & $-*$ \\
\hline Marital status & $\begin{array}{l}\text { Unmarried }(n=69) \\
\text { Married }(n=4 \mid 3) \\
\text { Living alone or widowed } \\
(n=25)\end{array}$ & $\begin{array}{l}5(7.2) \\
40(9.7) \\
3(12.0)\end{array}$ & $\begin{array}{l}64(92.8) \\
373(90.3) \\
22(88.0)\end{array}$ & 0.625 & 0.738 & $\_*$ & -* \\
\hline Family member & $\begin{array}{l}<5 \text { Individuals }(n=376) \\
\geq 5 \text { Individuals }(n=|3|)\end{array}$ & $\begin{array}{l}37(9.8) \\
\text { II }(8.4)\end{array}$ & $\begin{array}{l}339(90.2) \\
120(91.6)\end{array}$ & 0.236 & 0.627 & 0.84 & $0.415,1.699$ \\
\hline Body mass index & $\begin{array}{l}\text { Underweight }(n=53) \\
\text { Normal }(n=300) \\
\text { Overweight }(n=154)\end{array}$ & $\begin{array}{l}7(13.2) \\
34(11.3) \\
7(4.5)\end{array}$ & $\begin{array}{l}46(86.8) \\
266(88.7) \\
147(95.5)\end{array}$ & 6.436 & 0.04 & $\_*$ & $\_*$ \\
\hline Daily drinking water & $\begin{array}{l}\text { Boiled water }(n=438) \\
\text { Unboiled water }(n=69)\end{array}$ & $\begin{array}{l}33(7.5) \\
15(21.7)\end{array}$ & $\begin{array}{l}405(92.5) \\
54(78.3)\end{array}$ & 14.033 & $<0.001$ & 3.409 & $1.739,6.683$ \\
\hline Source of drinking water & $\begin{array}{l}\text { Well water }(n=7) \\
\text { Tap water }(n=500)\end{array}$ & $\begin{array}{l}0(0.0) \\
48(9.6)\end{array}$ & $\begin{array}{l}7(100.0) \\
452(90.4)\end{array}$ & $-*$ & 0.999 & $-*$ & $-*$ \\
\hline Toilet types & $\begin{array}{l}\text { Water closet }(n=149) \\
\text { Waterless toilet }(n=358)\end{array}$ & $\begin{array}{l}5(3.4) \\
43(12.0)\end{array}$ & $\begin{array}{l}144(96.6) \\
315(88.0)\end{array}$ & 9.196 & 0.002 & 3.931 & $1.525,10.133$ \\
\hline Washing hands after defecation & $\begin{array}{l}\text { No }(n=189) \\
\text { Yes }(n=3 \mid 8)\end{array}$ & $\begin{array}{l}24(12.7) \\
24(7.5)\end{array}$ & $\begin{array}{l}165(87.3) \\
294(92.5)\end{array}$ & 3.67 & 0.055 & 0.561 & $0.309,1.02$ \\
\hline Raising livestock & $\begin{array}{l}\text { No }(n=196) \\
\text { Yes }(n=3 \mid 1)\end{array}$ & $\begin{array}{l}17(8.7) \\
31(10.0)\end{array}$ & $\begin{array}{l}179(91.3) \\
280(90.0)\end{array}$ & 0.235 & 0.628 & 1.166 & $0.627,2.168$ \\
\hline Keeping pets & $\begin{array}{l}\text { No }(n=347) \\
\text { Yes }(n=160)\end{array}$ & $\begin{array}{l}31(8.9) \\
17(10.6)\end{array}$ & $\begin{array}{l}368(91.1) \\
143(89.4)\end{array}$ & 0.365 & 0.545 & 1.212 & $0.65,2.26 I$ \\
\hline Contacting animals & $\begin{array}{l}\text { No }(n=203) \\
\text { Yes }(n=304)\end{array}$ & $\begin{array}{l}19(9.4) \\
29(9.5)\end{array}$ & $\begin{array}{l}184(90.6) \\
275(90.5)\end{array}$ & 0.005 & 0.946 & 1.021 & $0.556,1.876$ \\
\hline Chronic diarrhea in family members & $\begin{array}{l}\text { No }(n=485) \\
\text { Yes }(n=22)\end{array}$ & $\begin{array}{l}46(9.5) \\
2(9.1)\end{array}$ & $\begin{array}{l}439(90.5) \\
20(90.9)\end{array}$ & 0.004 & 0.951 & 0.954 & $0.216,4.213$ \\
\hline Anemia & $\begin{array}{l}\text { No }(n=445) \\
\text { Yes }(n=62)\end{array}$ & $\begin{array}{l}36(8.1) \\
12(19.4)\end{array}$ & $\begin{array}{l}409(91.9) \\
50(80.6)\end{array}$ & 8.057 & 0.005 & 2.727 & $1.332,5.581$ \\
\hline
\end{tabular}

(Continued) 
Table I (Continued).

\begin{tabular}{|c|c|c|c|c|c|c|c|}
\hline \multirow{2}{*}{\multicolumn{2}{|c|}{ Variable }} & \multicolumn{2}{|c|}{$\begin{array}{l}\text { Blastocysts sp. } \\
\text { Infections (n, \%) }\end{array}$} & \multicolumn{4}{|c|}{ Univariate Analysis } \\
\hline & & \multirow{2}{*}{$\begin{array}{l}\text { Positive } \\
(n=48)\end{array}$} & \multirow{2}{*}{$\begin{array}{l}\text { Negative } \\
(n=459)\end{array}$} & \multirow{2}{*}{$\frac{\chi^{2}}{1.304}$} & \multirow{2}{*}{$\begin{array}{l}P \\
0.253\end{array}$} & \multirow{2}{*}{$\begin{array}{l}\text { OR } \\
1.6\end{array}$} & \multirow{2}{*}{$\begin{array}{l}95 \% \mathrm{Cl} \text { for } \\
\text { OR } \\
0.7 \mathrm{I}, 3.607\end{array}$} \\
\hline Chronic diarrhea & $\begin{array}{l}\text { No }(n=448) \\
\text { Yes }(n=59)\end{array}$ & & & & & & \\
\hline Eating raw or semi-raw meat & $\begin{array}{l}\text { Never }(n=429) \\
\text { Occasionally }(n=73) \\
\text { Frequently }(n=5)\end{array}$ & $\begin{array}{l}42(9.8) \\
6(8.2) \\
0(0.0)\end{array}$ & $\begin{array}{l}387(90.2) \\
67(91.8) \\
5(100.0)\end{array}$ & 1.185 & 0.553 & $-*$ & $-*$ \\
\hline Eating raw or semi-raw eggs & $\begin{array}{l}\text { Never }(n=500) \\
\text { Occasionally }(n=7) \\
\text { Frequently }(n=0)\end{array}$ & $\begin{array}{l}48(9.6) \\
0(0.0) \\
-\end{array}$ & $\begin{array}{l}452(90.4) \\
7(100.0) \\
-\end{array}$ & $-*$ & 0.999 & 0.904 & $0.879,0.93$ \\
\hline $\begin{array}{l}\text { Eating raw or semi-raw dairy } \\
\text { products }\end{array}$ & $\begin{array}{l}\text { Never }(n=503) \\
\text { Occasionally }(n=4) \\
\text { Frequently }(n=0)\end{array}$ & $\begin{array}{l}48(9.5) \\
0(0.0) \\
-\end{array}$ & $\begin{array}{l}455(90.5) \\
4(100.0) \\
-\end{array}$ & $-*$ & 0.999 & 0.905 & $0.879,0.931$ \\
\hline Eating raw vegetables or fruits & $\begin{array}{l}\text { Never }(n=470) \\
\text { Occasionally }(n=26) \\
\text { Frequently }(n=I I)\end{array}$ & $\begin{array}{l}45(9.6) \\
1(3.8) \\
2(18.2)\end{array}$ & $\begin{array}{l}425(90.4) \\
25(96.2) \\
9(81.8)\end{array}$ & 2.005 & 0.367 & $-*$ & $-*$ \\
\hline
\end{tabular}

Note: *Data unavailable or not calculated.

Abbreviations: $O R$, odds ratio; $\mathrm{Cl}$, confidence interval.

gender, ethnicity, residence, education level, marital status, family size, source of drinking water, raising livestock, keeping pets, contact with animals, chronic diarrhea in family members, chronic diarrhea, eating raw/semi-raw meat, eating raw or semi-raw eggs, eating raw/semi-raw dairy products, eating raw vegetables/fruits or washing hands after defecation $(P>0.05)$, while the prevalence of Blastocystis sp. infections significantly correlated with type of daily drinking water, toilet type, anemia and body mass index $(P<0.05)$ (Table 1$)$. Then, five variables were included in the multivariate logistic regression analysis, including washing hands after defecation, daily drinking water, toilet type, anemia and body mass index, and toilet type $(O R=3.248,95 \%$ $C I: 1.245-8.473)$, anemia $(O R=2.601,95 \% C I: 1.245-$ $8.473)$ and type of daily drinking water $(O R=3.11,95 \%$ $C I$ : 1.557-6.213) were identified as risk factors of Blastocystis sp. infections (Table 2).

\section{Association Between Blastocystissp. Infection and Clinical Manifestations}

There were no associations of Blastocystis sp. infections with abdominal distension, loss of appetite, itchy skin, perianal pruritus or constipation $(P>0.05)$ (Table 3$)$.

\section{Prevalence of Blastocystis sp. Subtypes}

Among the 48 Blastocystis isolates, there were four subtypes characterized (Figure 1), including ST3 ( $\mathrm{n}=24,50 \%), \mathrm{ST} 1(\mathrm{n}$ $=16,33.33 \%)$, ST4 $(\mathrm{n}=7,14.58 \%)$ and ST2 subtypes $(\mathrm{n}=1$, $2.08 \%)$. The prevalence of Blastocystis subtypes varied among participants $\left(\chi^{2}=26.118, P<0.001\right)$, and the highest prevalence was estimated for the ST3 subtype (4.73\%, 95\% CI: $3.20-6.94 \%)$, followed by the ST1 (3.16\%, 95\% CI: 1.95-5.07\%) and ST4 subtypes (1.38\%, 95\% CI: $0.07-2.82 \%)$ and the lowest for the ST2 subtype $(0.2 \%, 95 \% C I: 0.00$ $1.11 \%)$. We found no age- $(P=0.316)$, gender- $(P=0.29)$,

Table 2 Multivariate Logistic Regression Analysis of Factors Affecting Blastocystis sp. Infections

\begin{tabular}{|l|l|l|l|l|l|l|}
\hline Variables & Beta & SE & Wald & $\boldsymbol{P}$ & OR & $\begin{array}{l}\text { 95\% CI for } \\
\text { OR }\end{array}$ \\
\hline $\begin{array}{l}\text { Daily drinking } \\
\text { water }\end{array}$ & 1.135 & 0.353 & 10.329 & 0.001 & 3.11 & $1.557,6.213$ \\
\hline Toilet types & 1.178 & 0.489 & 5.799 & 0.016 & 3.248 & $1.245,8.473$ \\
\hline Anemia & 0.956 & 0.378 & 6.394 & 0.011 & 2.601 & $1.24,5.457$ \\
\hline Constant & - & 1.09 & 39.75 & $<$ & 0.001 & $-*$ \\
\hline
\end{tabular}

Note: *Data unavailable or not calculated.

Abbreviations: $S E$, standard error of mean; $C$, confidence interval; $O R$, odds ratio. 
Table 3 Association Between Clinical Manifestations and Blastocystis sp. Infection

\begin{tabular}{|c|c|c|c|c|c|c|c|}
\hline \multicolumn{2}{|l|}{ Variable } & \multicolumn{2}{|c|}{ Blastocystis sp. Infection (n, \%) } & \multirow{3}{*}{$\begin{array}{l}\chi^{2} \\
3.324\end{array}$} & \multirow{3}{*}{$\begin{array}{l}P \\
0.068\end{array}$} & \multirow{3}{*}{$\begin{array}{l}\text { OR } \\
0.284\end{array}$} & \multirow{3}{*}{$\begin{array}{l}95 \% \mathrm{Cl} \text { for } \mathrm{OR} \\
0.067,1.199\end{array}$} \\
\hline & & \multirow{2}{*}{$\begin{array}{l}\text { Positive }(n=48) \\
46(10.4) \\
2(3.2)\end{array}$} & \multirow{2}{*}{$\begin{array}{l}\text { Negative }(n=459) \\
398(89.6) \\
61(96.8)\end{array}$} & & & & \\
\hline Abdominal distension & $\begin{array}{l}\text { No }(n=444) \\
\text { Yes }(n=63)\end{array}$ & & & & & & \\
\hline Loss of appetite & $\begin{array}{l}\text { No }(n=416) \\
\text { Yes }(n=91)\end{array}$ & $\begin{array}{l}41(9.9) \\
7(7.7)\end{array}$ & $\begin{array}{l}375(90.1) \\
84(92.3)\end{array}$ & 0.408 & 0.523 & 0.762 & $0.33,1.758$ \\
\hline Itchy skin & $\begin{array}{l}\text { No }(n=445) \\
\text { Yes }(n=62)\end{array}$ & $\begin{array}{l}43(9.7) \\
5(8.1)\end{array}$ & $\begin{array}{l}402(90.3) \\
57(91.9)\end{array}$ & 0.162 & 0.687 & 0.82 & $0.312,2.156$ \\
\hline Perianal pruritus & $\begin{array}{l}\text { No }(n=479) \\
\text { Yes }(n=28)\end{array}$ & $\begin{array}{l}48(10.0) \\
0(0.0)\end{array}$ & $\begin{array}{l}431(90.0) \\
28(100.0)\end{array}$ & $-*$ & 0.079 & $-*$ & $-*$ \\
\hline Constipation & $\begin{array}{l}\text { No }(n=452) \\
\text { Yes }(n=55)\end{array}$ & $\begin{array}{l}41(9.1) \\
7(12.7)\end{array}$ & $\begin{array}{l}411(90.9) \\
48(87.3)\end{array}$ & 0.765 & 0.382 & 1.462 & $0.621,3.419$ \\
\hline
\end{tabular}

Note: *Data unavailable or not calculated.

Abbreviations: $O R$, odds ratio; $\mathrm{Cl}$, confidence interval.

weight- $(P=0.437)$, or height-specific prevalence of Blastocystis subtypes $(P=0.278)$. In addition, there was no gender-specific prevalence of Blastocystis ST1 (3.1\% vs $3.2 \%, P=0.917)$, ST2 (0 vs $0.4 \%, P=0.487)$, ST3 $(3.1 \%$ vs $6.5 \%, P=0.071)$ or ST 4 subtypes $(2.3 \%$ vs $0.4 \%$, $P=0.123)$.

\section{Association Between Blastocystis Subtypes and Clinical Manifestations}

Infection with the Blastocystis ST1 subtype was not found to correlate with abdominal pain $(P=0.491)$, lack of appetite $(P=0.999)$, itchy skin $(P=0.999)$, perianal pruritus $(P=0.999)$ or constipation $(P=0.689)$, while ST1 subtype infection was associated with anemia $(P=$ 0.008). The ST3 subtype infection had no associations with abdominal pain $(P=0.781)$, lack of appetite $(P=$ $0.281)$, itchy skin $(P=0.999)$, perianal pruritus $(P=$ $0.387)$, constipation $(P=0.316)$ or anemia $(P=0.1)$, and no associations of ST4 subtype infections were seen with abdominal pain $(P=0.327)$, anemia $(P=0.999)$, lack of appetite $(P=0.615)$, itchy skin $(P=0.999)$, perianal pruritus $(P=0.999)$ or constipation $(P=0.555)$.

\section{Discussion}

As a unicellular parasite that colonizes the intestines of humans and a wide range of non-human animals, Blastocystis sp. is widely distributed in the world, and the prevalence of this parasite infection has shown a remarkable rise during the past decade. ${ }^{4}$ Epidemiological data show that Blastocystis sp. is highly prevalent in tropical areas, notably in developing countries with poor hygiene conditions. ${ }^{31}$ Although the pathogenic potential of Blastocystis sp. continues to be debated, this parasite is widely accepted as a pathogenic contributor to diarrhea and abdominal pain in humans. ${ }^{2,7}$ Notably, Blastocystis sp. infections may induce obvious diarrhea in immunocompromised patients, such as HIV/AIDS and cancer patients. ${ }^{32}$ As a genetically diverse parasite, there have been 17 subtypes of Blastocystis sp. characterized based on the SSU rRNA gene analysis until now. ${ }^{33}$ Blastocystis ST1 to ST9 and ST12 have been identified in both humans and non-human animals, and there is a risk of zoonotic transmission of ST1-ST8 subtypes to humans. ${ }^{33}$

In China, the prevalence of Blastocystis sp. infections has been investigated in diverse populations. ${ }^{21}$ In two ethnic minority groups on both sides of the ChinaMyanmar border, PCR assay detected a $6.29 \%$ overall prevalence of Blastocystis sp. infections in the study populations, with $4.50 \%$ in Yao ethnic participants and $9.3 \%$ in Wa ethnic participants. ${ }^{22}$ Among the HIV/AIDS patients living in Tengchong city, southwestern China and Fuyang city, central China, the detection rates of Blastocystis sp. were $3.86 \%$ and $6.78 \%$, respectively. ${ }^{24,34}$ In Huainan city, Anhui province, central China, iodine staining and hematoxylin staining detected $1 \%, 1 \%, 0$ and $5.96 \%$ prevalence of Blastocystis sp. infections among infants, pupils, middle school students and the patients with diarrhea, respectively. ${ }^{35}$ In a rural district of West China, the detection rate of Blastocystis sp. was $1.37 \%$ using the culture method. ${ }^{36}$ Among 850 children with acute diarrhea at ages 


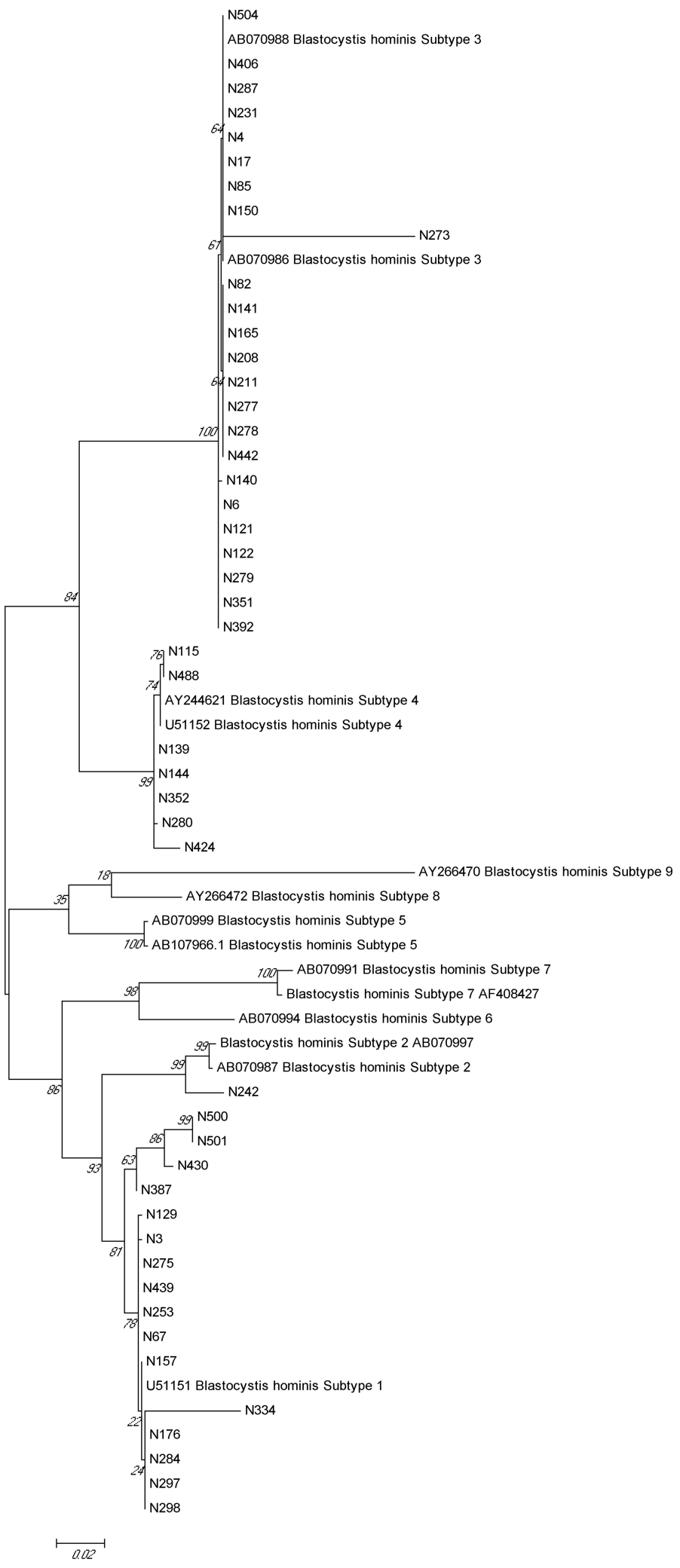

Figure I Evolutionary relationships among Blastocystis subtypes shown by the maximum likelihood method. The percentage of replicate trees in which the associated Blastocystis subtypes are clustered together in the bootstrap test (I,000 iterations) is indicated next to the branches. 
of one month to 5 years and 170 healthy controls sampled from four sentinel hospitals in Kunming, Yunnan province, southwestern China, PCR assay detected 3.1\% prevalence of Blastocystis sp. infections in children with diarrhea and $0.5 \%$ in controls $(O R=4.7,95 \% \quad C I: 1.01-112) .{ }^{37}$ However, there is little knowledge on the prevalence and risk factors of Blastocystis sp. infections, as well as Blastocystis sp. subtypes among general populations in southeastern China.

In this study, PCR assay was employed to identify Blastocystis $\mathrm{sp}$. infections among general populations sampled from two suburban towns of Tengchong city, Yunnan province, southwestern China, and the detection rate of Blastocystis sp. was $9.47 \%$ in the study subjects, which is similar to the prevalence in Wa ethnic populations living in the province $(9.3 \%),{ }^{22}$ but lower than in Eryuan county $(18.4 \%),{ }^{27}$ Menghai county $(32.6 \%)^{27}$ and Xishuangbanna prefecture $(32.6 \%),{ }^{26}$ and higher than in HIV/AIDS patients and children with acute diarrhea from the province. ${ }^{34,37}$ The variation in the prevalence of Blastocystis sp. infections may be attributed to the geographical locations, study subjects and diagnostic techniques. ${ }^{21}$

Previous studies have identified a diverse range of risk factors for Blastocystis sp. infections. ${ }^{22-25}$ In this study, drinking unboiled water was found to correlate with a high prevalence of Blastocystis sp. infections, which was consistent with previous studies. ${ }^{26}$ Although Chinese populations have a habit of drinking boiled water, some individuals living in remote areas prefer drinking unboiled raw water directly, which increases the likelihood of intestinal protozoan infections. ${ }^{26}$ Improving the disinfection and management of drinking water may reduce the prevalence of Blastocystis sp. infections. $^{38}$

In this study, we found that the participants using waterless toilets had a significantly greater prevalence of Blastocystis sp. infections than those using water closets $(P=0.002)$. The study sites are agricultural areas located in remote, rural and impoverished regions of Yunnan province, southwestern China, where waterless toilets have not been completely replaced by water closets. ${ }^{39}$ As a common zoonotic pathogen, Blastocystis sp. is widespread in livestock, and Blastocystis sp. cannot be effectively killed in human or livestock feces without high temperature composting or biogas fermentation. ${ }^{4}$ If feces containing Blastocystis sp. are flushed into the fields through rainfall, this may contaminate vegetables, notably broadleaf vegetables, thereby inducing Blastocystis sp. infections via the fecal-oral route. ${ }^{4}$ Hence, using sanitary toilets, agricultural production with machines instead of livestock and harmless disposal of livestock fertilizer are likely to reduce Blastocystis sp. infections, and improving environmental hygiene is of great importance for the prevention of Blastocystis sp. infections.

In the current study, the participants with anemia were found to have a higher prevalence of Blastocystis sp. infections than in those without anemia, and multivariate logistic regression analysis identified anemia as a risk factor of Blastocystis sp. infections. It is reported that individuals suffering from iron deficiency anemia are more susceptible to have Blastocystis sp. infections than non-anemic controls (40\% vs $6.3 \% ; P<0.000,1)$, and Blastocystis sp. infection has been identified as a contributing factor to the pathogenesis of iron deficiency anemia in pregnant women. ${ }^{40}$ In this study, we found a correlation between ST1 subtype infection and anemia $(P=0.008)$; however, the predominant ST3 subtype, ST2 or ST4 all had no associations with anemia. This is different from previous findings in pregnant women reporting no correlation between Blastocystis subtypes and anemia. $^{40}$ However, the causal mechanism underlying Blastocystis sp. infections and anemia remains to be demonstrated. Previous studies have shown that Blastocystis sp. infection is significantly associated with abdominal pain in symptomatic French populationsn; ${ }^{41}$ however, the present study examined no associations of Blastocystis sp. infection with any clinical manifestations. Further studies to evaluate the correlation between Blastocystis sp. infection and clinical syndromes seem justified.

To date, six Blastocystis subtypes (ST1 to ST6) have been identified in humans in China, and ST3 is the most dominant subtype. $^{21}$ In this study, four subtypes (ST1 to ST4) were characterized in 48 Blastocystis isolates, and ST3 was found to be the dominant subtype, which was in agreement with the findings from the same province, ${ }^{22,26,27}$ and the isolates from kindergarten children in southern Xinjiang, northwestern China $^{42}$ and college students in Guangxi, northern China, ${ }^{43}$ as well as from Zhejiang province and Shanghai municipality, eastern China. ${ }^{27}$ However, ST1 was also reported as the dominant Blastocystis subtype in China. ${ }^{44}$ This variation may be attributable to Blastocystis isolates from different populations and various geographical locations.

Previous studies have demonstrated the correlations between Blastocystis subtypes and clinical manifestations. ${ }^{45,46}$ Blastocystis subtype ST1, ST2, ST4 and ST6 are reported to correlate with gastrointestinal symptoms, ${ }^{47,48}$ and ST2 subtype infection was associated with gastrointestinal and urticarial symptoms, ${ }^{49}$ while ST1, 
ST3 and ST7 were linked with irritable bowel syndrome. ${ }^{50,51}$ In this study, we found that ST1 subtype infection was associated with anemia $(P=0.008)$, while no associations were seen between Blastocystis subtypes ST3 or ST4 and any clinical symptoms. Our data demonstrate the pathogenic role of Blastocystis subtype ST1 in anemia. Further mechanistic studies are required to investigate the distinct pathogenicity of Blastocystis subtypes and the associations between Blastocystis subtypes and anemia.

This study has some limitations. First, this is a crosssectional study, and we are unable to draw causal conclusions. Second, only a fecal specimen was collected from each participant. Third, the number of positive samples of ST1, ST2, ST3 and ST4 was small, so that data sparsity resulted in unstable estimates for the association between Blastocystis subtypes and clinical symptoms.

In summary, the results of the present study demonstrate a high prevalence of Blastocystis sp. infections among general populations in Yunnan province, southwestern China, and toilet type, anemia and type of daily drinking water are risk factors of Blastocystis sp. infections. In addition, there were Blastocystis subtypes (ST1, ST2, ST3 and ST4) characterized in the study populations, and ST3, as the dominant subtype, correlates with anemia. Improving hygiene conditions, developing healthy lifestyles and intensifying health education programs are strongly recommended to reduce the prevalence and transmission potential of Blastocystis sp. infections.

\section{Acknowledgments}

We would like to express our sincere thanks to Tengchong Municipal People's Hospital, Tengchong Hospital of Traditional Chinese Medicine and Tengchong Municipal Center for Disease Control and Prevention during the stool specimen collection and epidemiological investigations. This study was supported by the grants from the National Natural Science Foundation of China (grant no. 81473022) and Jiangsu Provincial Young Talents in Medical Sciences (grant no. QNRC2016621).

\section{Disclosure}

The authors declare no competing interests for this work.

\section{References}

1. Plutzer J, Karanis P. Neglected waterborne parasitic protozoa and their detection in water. Water Res. 2016;101:318-332. doi:10.1016/j. watres.2016.05.085
2. Skotarczak B. Genetic diversity and pathogenicity of Blastocystis. Ann Agric Environ Med. 2018;25(3):411-416. doi:10.26444/aaem/ 81315

3. Clark CG, van der Giezen M, Alfellani MA, Stensvold CR. Recent developments in Blastocystis research. Adv Parasitol. 2013;82:1-32.

4. Stensvold CR, Clark CG. Current status of Blastocystis: a personal view. Parasitol Int. 2016;65(6):763-771. doi:10.1016/j.parint.2016. 05.015

5. Wawrzyniak I, Poirier P, Viscogliosi E, et al. Blastocystis, an unrecognized parasite: an overview of pathogenesis and diagnosis. Ther Adv Infect Dis. 2013;1(5):167-178.

6. Ocaña-Losada C, Cuenca-Gómez JA, Cabezas-Fernández MT, et al. Clinical and epidemiological characteristics of intestinal parasite infection by Blastocystis hominis. Rev Clin Esp. 2018;218 (3):115-120. doi:10.1016/j.rce.2018.01.003

7. Kumarasamy V, Anbazhagan D, Subramaniyan V, Vellasamy S. Blastocystis sp., parasite associated with gastrointestinal disorders: an overview of its pathogenesis, immune modulation and therapeutic strategies. Curr Pharm Des. 2018;24(27):3172-3175. doi:10.2174/ 1381612824666180807101536

8. Kesuma Y, Firmansyah A, Bardosono S, Sari IP, Kurniawan A. Blastocystis ST-1 is associated with irritable bowel syndrome-diarrhoea (IBS-D) in Indonesian adolescences. Parasite Epidemiol Control. 2019;6:e00112. doi:10.1016/j.parepi.2019.e00112

9. Yakoob J, Jafri W, Beg MA, et al. Irritable bowel syndrome: is it associated with genotypes of Blastocystis hominis. Parasitol Res. 2010;106(5):1033-1038. doi:10.1007/s00436-010-1761-x

10. Kök M, Çekin Y, Çekin AH, Uyar S, Harmandar F, Şahintürk Y. The role of Blastocystis hominis in the activation of ulcerative colitis. Turk J Gastroenterol. 2019;30(1):40-46.

11. Verma R, Delfanian K. Blastocystis hominis associated acute urticaria. Am J Med Sci. 2013;346(1):80-81. doi:10.1097/MAJ.0b $013 \mathrm{e} 3182801478$

12. Hameed DM, Hassanin OM, Zuel-Fakkar NM. Association of Blastocystis hominis genetic subtypes with urticaria. Parasitol Res. 2011;108(3):553-560. doi:10.1007/s00436-010-2097-2

13. Zuel-Fakkar NM, Abdel Hameed DM, Hassanin OM. Study of Blastocystis hominis isolates in urticaria: a case-control study. Clin Exp Dermatol. 2011;36(8):908-910. doi:10.1111/j.13652230.2011.04127.x

14. Bahrami F, Babaei E, Badirzadeh A, Riabi TR, Abdoli A. Blastocystis, urticaria, and skin disorders: review of the current evidences. Eur J Clin Microbiol Infect Dis. 2020;39(6):1027-1042. doi:10.1007/s10096-019-03793-8

15. Singh A, Priyadarshi K, Rai T, Banerjee T. A case report of Blastocystis infection and Steven Johnson's syndrome. Trop Biomed. 2019;36(4):987-992.

16. Berkman DS, Lescano AG, Gilman RH, Lopez SL, Black MM. Effects of stunting, diarrhoeal disease, and parasitic infection during infancy on cognition in late childhood: a follow-up study. Lancet. 2002;359(9306):564-571. doi:10.1016/S0140-6736(02)07744-9

17. Olaya J, Sarmiento D, Jaramillo JF, Ordoñez GA, Cortés F, Sánchez LK. Intestinal parasitic infections and associated factors in children of three rural schools in Colombia. A cross-sectional study. PLoS One. 2019;14(7):e0218681. doi:10.1371/journal.pone.0218681

18. Andersen LO, Stensvold CR, Kraft CS. Blastocystis in health and disease: are we moving from a clinical to a public health perspective? J Clin Microbiol. 2016;54(3):524-528. doi:10.1128/ JCM.02520-15

19. Dogruman-Al F, Dagci H, Yoshikawa H, Kurt O, Demirel M. A possible link between subtype 2 and asymptomatic infections of Blastocystis hominis. Parasitol Res. 2008;103(3):685-689.

20. Hussein EM, Hussein AM, Eida MM, Atwa MM. Pathophysiological variability of different genotypes of human Blastocystis hominis Egyptian isolates in experimentally infected rats. Parasitol Res. 2008;102(5):853-860. doi:10.1007/s00436-007-0833-z 
21. Deng L, Chai Y, Zhou Z, et al. Epidemiology of Blastocystis sp. infection in China: a systematic review. Parasite. 2019;26:41. doi:10.1051/parasite/2019042

22. Gong B, Liu X, Wu Y, et al. Prevalence and subtype distribution of Blastocystis in ethnic minority groups on both sides of the China-Myanmar border, and assessment of risk factors. Parasite. 2019;26:46. doi:10.1051/parasite/2019046

23. Chen TL, Chan CC, Chen HP, et al. Clinical characteristics and endoscopic findings associated with Blastocystis hominis in healthy adults. Am J Trop Med Hyg. 2003;69(2):213-216. doi:10.4269/ ajtmh.2003.69.213

24. Zhang SX, Yu YF, Wu XP, et al. Epidemiological characteristics and risk factors of Blastocystis hominis infection among patients with HIV/AIDS in Fuyang City Anhui Province. Zhongguo Xue Xi Chong Bing Fang Zhi Za Zhi. 2019;31(5):498-503.

25. Kang JM, Li YT, Chen R, et al. Prevalence and risk factors of Blastocystis hominis infection in inpatients in Jiangjin District, Chongqing City. Zhongguo Xue Xi Chong Bing Fang Zhi Za Zhi. 2019;31(5):479-485.

26. Li LH, Zhou XN, Du ZW, et al. Molecular epidemiology of human Blastocystis in a village in Yunnan province, China. Parasitol Int. 2007;56(4):281-286. doi:10.1016/j.parint.2007.06.001

27. Li LH, Zhang XP, Lv S, et al. Cross-sectional surveys and subtype classification of human Blastocystis isolates from four epidemiological settings in China. Parasitol Res. 2007;102(1):83-90. doi:10.1007/ s00436-007-0727-0

28. Zhang SX, Yang CL, Gu WP, et al. Case-control study of diarrheal disease etiology in individuals over 5 years in southwest China. Gut Pathog. 2016;8:58. doi:10.1186/s13099-016-0141-1

29. Wong KH, Ng GC, Lin RT, Yoshikawa H, Taylor MB, Tan KS. Predominance of subtype 3 among Blastocystis isolates from a major hospital in Singapore. Parasitol Res. 2008;102(4):663-670. doi:10.1007/s00436-007-0808-0

30. Hattori M, Sakaki Y. Dideoxy sequencing method using denatured plasmid templates. Anal Biochem. 1986;152(2):232-238. doi:10.1016/0003-2697(86)90403-3

31. Javanmard E, Niyyati M, Ghasemi E, Mirjalali H, Asadzadeh Aghdaei H, Zali MR. Impacts of human development index and climate conditions on prevalence of Blastocystis: a systematic review and meta-analysis. Acta Trop. 2018;185:193-203. doi:10.1016/j. actatropica.2018.05.014

32. Marcos LA, Gotuzzo E. Intestinal protozoan infections in the immunocompromised host. Curr Opin Infect Dis. 2013;26 (4):295-301.

33. Stensvold CR, Suresh GK, Tan KS, et al. Terminology for Blastocystis subtypes-a consensus. Trends Parasitol. 2007;23 (3):93-96. doi:10.1016/j.pt.2007.01.004

34. Zhang SX, Kang FY, Chen JX, Tian LG, Geng LL. Risk factors for Blastocystis infection in HIV/AIDS patients with highly active antiretroviral therapy in Southwest China. Infect Dis Poverty. 2019;8 (1):89. doi:10.1186/s40249-019-0596-7

35. Wang KX, Li CP, Wang J, Cui YB. Epidemiological survey of Blastocystis hominis in Huainan City, Anhui Province, China. World J Gastroenterol. 2002;8(5):928-932. doi:10.3748/wjg.v8. i5.928
36. Tang N, Luo NJ. A cross-sectional study of intestinal parasitic infections in a rural district of west China. Can J Infect Dis. 2003;14 (3):159-162. doi:10.1155/2003/721930

37. Zhang SX, Zhou YM, Xu W, et al. Impact of co-infections with enteric pathogens on children suffering from acute diarrhea in southwest China. Infect Dis Poverty. 2016;5(1):64. doi:10.1186/s40249016-0157-2

38. Sekar U, Shanthi M. Blastocystis: consensus of treatment and controversies. Trop Parasitol. 2013;3(1):35-39. doi:10.4103/22295070.113901

39. Feng L, Yu J, Huang GF. Toilet retrofitting in rural areas of Yunnan province: a cross-sectional survey. Chin J Public Health. 2019;35 (5):615-617.

40. El Deeb HK, Salah-Eldin H, Khodeer S. Blastocystis hominis as a contributing risk factor for development of iron deficiency anemia in pregnant women. Parasitol Res. 2012;110(6):2167-2174. doi:10.1007/s00436-011-2743-3

41. El Safadi D, Cian A, Nourrisson C, et al. Prevalence, risk factors for infection and subtype distribution of the intestinal parasite Blastocystis sp. from a large-scale multi-center study in France. BMC Infect Dis. 2016;16(1):451. doi:10.1186/s12879-016-1776-8

42. Qi M, Wei Z, Zhang Y, et al. Genetic diversity of Blastocystis in kindergarten children in southern Xinjiang, China. Parasit Vectors. 2020;13(1):15. doi:10.1186/s13071-020-3890-0

43. Zhan TZ, Liu T, Shi HH, He SS, Yan H, Liu DY. PCR-based genotype classification of Blastocystis hominis isolates from college students of Guangxi. Zhongguo Ji Sheng Chong Xue Yu Ji Sheng Chong Bing Za Zhi. 2014;32(3):209-211.

44. Yan Y, Su S, Lai R, et al. Genetic variability of Blastocystis hominis isolates in China. Parasitol Res. 2006;99(5):597-601. doi:10.1007/ s00436-006-0186-z

45. Tan KS, Mirza H, Teo JD, Wu B, Macary PA. Current views on the clinical relevance of Blastocystis spp. Curr Infect Dis Rep. 2010;12 (1):28-35. doi:10.1007/s11908-009-0073-8

46. Salvador F, Sulleiro E, Sánchez-Montalvá A, et al. Epidemiological and clinical profile of adult patients with Blastocystis sp. infection in Barcelona, Spain. Parasit Vectors. 2016;9(1):548. doi:10.1186/ s13071-016-1827-4

47. Cakir F, Cicek M, Yildirim IH. Determination the subtypes of Blastocystis sp. and evaluate the effect of these subtypes on pathogenicity. Acta Parasitol. 2019;64(1):7-12.

48. Kaneda Y, Horiki N, Cheng X, Tachibana H, Tsutsumi Y. Serologic response to Blastocystis hominis infection in asymptomatic individuals. Tokai J Exp Clin Med. 2000;25(2):51-56.

49. Vogelberg C, Stensvold CR, Monecke S, et al. Blastocystis sp. subtype 2 detection during recurrence of gastrointestinal and urticarial symptoms. Parasitol Int. 2010;59:469-471. doi:10.1016/j. parint.2010.03.009

50. Poirier P, Wawrzyniak I, Vivarès CP, Delbac F, El Alaoui H, Knoll LJ. New insights into Blastocystis spp.: a potential link with irritable bowel syndrome. PLoS Pathog. 2012;8(3):e1002545. doi:10.1371/journal.ppat.1002545

51. Jimenez-Gonzalez DE, Martinez-Flores WA, Reyes-Gordillo J, et al. Blastocystis infection is associated with irritable bowel syndrome in a Mexican patient population. Parasitol Res. 2012;110(3):1269-1275. doi:10.1007/s00436-011-2626-7 


\section{Publish your work in this journal}

Risk Management and Healthcare Policy is an international, peerreviewed, open access journal focusing on all aspects of public health, policy, and preventative measures to promote good health and improve morbidity and mortality in the population. The journal welcomes submitted papers covering original research, basic science, clinical \& epidemiological studies, reviews and evaluations, guidelines, expert opinion and commentary, case reports and extended reports. The manuscript management system is completely online and includes a very quick and fair peer-review system, which is all easy to use. Visit http://www.dovepress.com/testimonials.php to read real quotes from published authors. 